\title{
Correction to: Advances in BeiDou Navigation Satellite System (BDS) and satellite navigation augmentation technologies
}

\author{
Rui Li ${ }^{1,2}$, Shuaiyong Zheng ${ }^{1}$, Ershen Wang ${ }^{3 *}$, Jinping Chen ${ }^{4}$, Shaojun Feng ${ }^{5}$, Dun Wang ${ }^{6}$ and Liwen Dai ${ }^{7}$
}

\section{Correction to: Satell Navig (2020) 1:12 https://doi.org/10.1186/s43020-020-00010-2}

In the original publication of this article (Li et al. 2020), there are several corrections as below:

1. In the first paragraph of this article, the sentence "In recent years, China has been actively promoting the construction and development of the BeiDou Navigation Satellite System (BDS), and by the end of the year 2000 the construction of BDS-1 was complete and BDS-1 began to provide GPS services for China." should be changed into "In recent years, China has been actively promoting the construction and development of the BeiDou Navigation Satellite System (BDS), and by the end of the year 2000 the construction of BDS-1 was completed and BDS-1 began to provide services for China." The word "GPS" should be removed.

2. In the first paragraph of this article, the sentence "With the rapid development of BDS in all aspects, the chief designer of BDS, Yang Changfeng, announced the initial operation of BDS-3 at the state council information office of China in early 2019, and since this time BDS-3 has been officially providing global positioning, navigation, and timing services." should be changed into "With the rapid development of BDS in all aspects, China

The original article can be found online at https://doi.org/10.1186/s43020-02000010-2.

*Correspondence: wanges_2016@126.com

${ }^{3}$ College of Electronic and Information Engineering, Shenyang Aerospace

University, No. 37 Daoyi South Street, Daoyi District, Shenyang, China

Full list of author information is available at the end of the article announced that the construction of the BDS-3 preliminary system was completed at the end of 2018."

3. In the subsection Research progress of Technologies of SBAS system segment, the sentence "Chen Jinping, chief engineer of the Beijing Satellite Navigation Center, both designed and carried out preliminary testing on BDSBAS, producing a general design for BDSBAS including the system work mode, information processing mode, and analysis (Chen 2019), as shown in Fig. 3.", needs to be changed to "The design and preliminary test of BDSBAS was introduced, including system work mode, information processing mode and performance analysis (Chen 2019), as shown in Fig. 3."

4. In the subsection Research progress of Technologies of GBAS system segment, the sentence "Geng Yongchao, a senior engineer at the CETC Northwest Group Co., LTD, developed GBAS for civil aviation, including the concept of using GBAS for civil aviation, the civil aviation GBAS architecture, and progress in GBAS., needs to be changed to "GBAS for civil aviation was introduced, including the concept of using GBAS for civil aviation, the civil aviation GBAS architecture, and the progress in GBAS."

5. In the subsection Research progress of Technologies of GBAS system segment, the sentence "Cai Yi, a chief designer at the China Research \& Development Academy of Machinery Equipment, developed NBGAS, with test equipment and a user terminal as shown in Fig. 8., needs to be changed to "The composition, principle and 
application of NBGAS with test equipment and user terminals was introduced, as shown in Fig. 8."

6. In the subsection Research progress of Technologies of GBAS system segment, the sentence "The real-time positioning accuracy for NBGAS was tested at the meter level, decimeter level, centimeter level, and post-processing millimeter level augmentation by Cai Yi., should be changed to "The real-time positioning accuracy for NBGAS was tested at the meter level, decimeter level, centimeter level, and post-processing millimeter level".

7. In the subsection Research progress of User segment technologies, the sentence "The initial operation of BDS-3 at was announced at the state council information office of China in early 2019, and BDS can provide basic navigation services globally., has to be changed to "The construction of the BDS-3 preliminary system was completed in the end of 2018."

The authors sincerely apologize for the inconvenience caused to the readers.

\section{Author details}

${ }^{1}$ School of Electronic and Information Engineering, Beihang University, No. 37 Xueyuan Road, Haidian District, Beijing, China. ${ }^{2}$ Suzhou Institute, Beihang University, Suzhou 215200, China. ${ }^{3}$ College of Electronic and Information

Engineering, Shenyang Aerospace University, No. 37 Daoyi South Street, Daoyi District, Shenyang, China. ${ }^{4}$ Beijing Satellite Navigation Center, No. 22 Beiqing Road, Haidian District, Beijing, China. ${ }^{5}$ Qianxun Spatial Intelligence Inc., C5 Building, No. 1688-38 North Guoquan Road, Yangpu District, Shanghai, China. ${ }^{6}$ Space Star Technology Co., Ltd., Blue Lake Industry Park, Haidian District, Beijing, China. ${ }^{7}$ John Deere - Intelligent Solution Group, 20780 Madrona Avenue, Torrance, CA, USA.

Published online: 31 March 2020

\section{Reference \\ Li, R., et al. (2020). Satell Navig, 1, 12.}

\section{Publisher's Note}

Springer Nature remains neutral with regard to jurisdictional claims in published maps and institutional affiliations.

\section{Submit your manuscript to a SpringerOpen ${ }^{\circ}$ journal and benefit from:}

- Convenient online submission

- Rigorous peer review

- Open access: articles freely available online

- High visibility within the field

- Retaining the copyright to your article 